\title{
OXFORD OPHTHALMOLOGICAL CONGRESS
}

\author{
XXth ANNUAL MEETING
}

The XXth Annual Meeting of the Oxford Ophthalmological Congress was held at Oxford on July 10, 11, and 12 .

Members met informally at dinner on the 9 th, in the Hall of Keble College, which had again offered its hospitality as in former years. The advantage which is gained by the all too short stay in the College, where each member is assigned rooms and becomes for the time being an undergraduate again, is quite one of the features of this successful annual gathering of ophthalmic surgeons, which was founded by the late Robert Doyne in 1909. The proceedings of the Congress were held in the Department of Human Anatomy of the University, kindly lent for the purpose by Professor Arthur Thomson, to whom the Congress is under a deep debt of gratitude. In addition to the Scientific Museums, a Commercial Exhibition was on view, in which numerous wellknown firms of ophthalmic instrument makers displayed the latest forms of apparatus and instruments used in the speciality.

An unusually large number of foreign members and others resident abroad attended the Congress this year. Amongst these were Prof. Gonin, of Lausanne, Prof. Schüller, of Vienna, Dr. Harry Friedenwald, of Baltimore, Prof. Curran, of Kansas City, Dr. Bernard Samuels and Dr. Tyson, of New York, Dr. Derrick T. Vail, Jr., of Cincinnati, Dr. van Heuven, of Utrecht, and Dr. Andrè Patry, of Geneva.

The proceedings opened on Thursday, July 10, with a short address of welcome by the Master of the Congress, Mr. A. Bernard Cridland. Immediately following this, Dr. TraquaIr introduced, from the ophthalmological standpoint, a symposium on toxic amblyopia including retrobulbar neuritis. He was followed by Sir FARQUHAR BUZZARD, who discussed the matter from the point of view of the physician, and Prof. J. A. GunN amplified the subject from the pharmacological aspect. Dr. TraQuaIr in his remarks said that to the clinical ophthalmologist retrobulbar neuritis presented itself as a visual defect in the form of a central, or paracentral, scotoma not explained by visible ophthalmoscopic changes in the macular region. He spoke of the rapid onset and gradual recovery which is often complete, the defect varying from slight visual loss to complete blindness. The characters of the scotoma were predominant involvement of the area of the crossed fibres, and the importance of the detection of quadrantic or hemianopic features was shown. He said that the appearance of the optic disc may vary from normal to that of choked disc, or there may be pallor. 
The clinical picture varies considerably, irrespective of the different causes, but certain forms show features which are to some extent distinctive. In retrobulbar neuritis with myelitis the visual defect is bilateral and may exhibit quadrantic features indicating a chiasmal site. There is also gross swelling of the optic discs. The scotoma in Leber's disease is bilateral with a less pronounced tendency to recovery. In acute retrobulbar neuritis, the defect is unilateral, and the tendency to recovery very pronounced. The pathological basis of the disease is the formation of plaques in the optic nerve which have a special inclination to affect the papillo-macular fibres. As regards causation, retrobulbar neuritis may be regarded as a manifestation of disease elsewhere, rather than as a primary disease of the optic nerve, thus the cause is to be sought elsewhere in the body. Differences of opinion exist as to the relative importance of certain causes, such as multiple sclerosis and paranasal sinusitis, dental and tonsillar infections. The true cause may not be manifest for a long time. The diagnosis of the cause is based on the study of the eye symptoms and on general physical examination, together with that of the visual fields and the detection of quadrantic or hemianopic features in the scotoma. Radiograms are very useful and the danger of neglect of eye symptoms in favour of the search for a septic focus is to be deprecated. Prognosis is good in the acute form, and usually favourable in others; complete blindness, even of one eye, is a rare result.

The expression toxic amblyopia refers to partial blindness due to toxins in the circulation, but no distinct boundary exists between toxic amblyopia and retrobulbar neuritis; the pathological lesion has been found by Roenne to be the same in both. In tobacco amblyopia for example, blindness is never produced, and the influence of the physical condition of the patient should always be borne in mind. In quinine amblyopia, the visual defect is due to direct toxic action on the nerve elements, rather than to retinal ischaemia.

Sir FarquHAR Buzzard, in discussing the question from the point of view of the physician, quoted from a passage in a paper written by his father in the last century, emphasizing the importance of these ocular symptoms in certain nervous diseases.

He discussed the clinical aspects of these conditions from a neurological and general medical viewpoint.

Prof. GunN dwelt on the pharmacological considerations in these diseases and suggested a much closer co-operation between the pharmacologist and the ophthalmic surgeon, in fact the laboratory worker and the clinician should work hand-in-hand. The subject of quinine amblyopia was also commented upon.

The discussion was continued by Dr. Leighton Davies, 
especially with regard to contraction of the visual fields in certain conditions; Mr. Gray Clegg, Mr. Adams, Drs. Rosa Ford, and Andrè Patry, Mr. Montague Harston, Prof. Schüller, Messrs. Joseph, Browning, Harrison Butler, Greene, Cyril Walker, Young, Giri, Galloway, Haycraft, and Drs. Tyson, Primrose and Thakore.

Dr. Bernard Samuels read a paper on opacities in the vitreous, and showed some beautiful drawings of opacities in this medium and fully described their appearances and general character.

In the afternoon, Sir Oliver Lodge, F.R.S., gave a most interesting and lucid address entitled "Modern Theories on the Nature of Light," which was attentively followed by the large audience. He prefaced his remarks by saying he did not know how much his hearers knew, and trusted the address would not be too elementary! Which humorous quip appealed to those present. He first of all gave a short sketch of the corpuscular and wave theories, and the reasons why the wave theory must be true. He then proceeded to show reasons why the corpuscular theory must also be true. Modern attempts at the unification of these two theories were then fully described, together with a theory of the probable nature of vision. The interaction of matter and radiation were fully dealt with, and its consequences were described. At the conclusion a vote of thanks was proposed by Mr. Leslie Paton, President of the Ophthalmological Society of the United Kingdom, and seconded by Mr. CyrIL Walker. It was carried with acclamation.

In the Scientific Museum, Mr. Burdon Cooper showed the orthogon test, Mr. Arthur GreEne, a specimen of ciliary growth causing glaucoma, Dr. TraQuAIR, a model of a field of vision, and Mr. Alabaster, a stereoscope, useful in fusion training. Mr. TUdor Thomas gave a demonstration of live rabbits with transparent corneal grafts. Mr. ERNEST MADDOx showed a hand attachment for the wing test, together with a stereoscope.

In the afternoon, tea was provided for members and their friends at Worcester College, where they were received by the Provost, Mrs. Lys, and Mrs. Bernard Cridland.

In the evening the Annual Dinner of the Congress was held in the Hall of Keble College, under the Presidency of the Master. Among the guests present were Laura Lady Airedale, Sir Farquhar Buzzard, Prof. and Mrs. Schüller, Prof. Gonin, and Dr. Evans. The dinner was the largest ever held in connection with the Congress, 142 members and their guests being present. The Master in the course of his speech stated it was the 21st year of their history, although only the 20th meeting, as in 1926, there was no Congress on account of the English Speaking Ophthalmological Congress, which was held in London that year. He 
read a letter from the American Ambassador, regretting that absence abroad made it impossible for him to be present. A letter from the President of the Roentgenological Society of Vienna was also read congratulating the Congress on being the first of that speciality to place radiographic diagnosis in the forefront of their programme. Mr. CyRIL WALKER proposed the toast of the guests, and Prof. Schüller replied. At the conclusion of the speeches, Mr. Gray ClegG presented Mr. Cridland on behalf of the members of the Congress with a gold watch and a set of table silver as a memento of his yeoman work for 14 years as Secretary of the Congress, and Mr. GreEne, in addition, presented the MASTER and COUNCIL with a badge of office to be worn by the Master on future official occasions. He stated that subscriptions had come in from all over the world for this testimonial, which showed how much Mr. Cridland's strenuous work during so many years had been appreciated. Mr. Cridland, who was obviously much affected by this recognition of his work, replied in a charming little speech of thanks.

The design of the official badge, which is of silver gilt, has at the upper part an eye, and the lower two-thirds show the colours of the spectrum in radiating beams on which are the leaves of belladonna, cocaine and calabar bean.

On Friday morning an address was given by Prof. Schuller, of Vienna, on recent developments in radiology associated with ophthalmology. He first described in much detail the normal variations of the sphenoid and then passed on to a description of the inflammatory conditions and neoplasms of its sinus. Infiltrating processes were then discussed, and destruction of the bone due to intracranial tumours. Sinuscele of the sphenoid was then illustrated and deformities found in neurofibromatosis were described. Prof. Schüller, who spoke for an hour in faultless English without notes, was listened to with wrapt attention, and on his conclusion was accorded an ovation by his large audience. The paper was discussed by Dr. Bowie, Mr. Edmund Jones, Dr. Traquair, and Mr. Foster Moore.

The Doyne Memorial Lecture was given by Dr. HARRY FrIEDENWALD, of Baltimore, on pathological changes in the retinal blood vessels in arteriosclerosis and hypertension. The lecturer minutely described the eye changes found in these conditions, illustrating them with a number of lantern slides. It is impossible to abstract this address, which should be read in the original. Mr. P. Adams, the Deputy Master, and Dr. Traguair proposed and seconded a vote of thanks to the lecturer.

On Friday afternoon, an address was given by Prof. Jules Gonis, of Lausanne, on detachment of the retina and its treatment. He described how he recognized the truth of Leber's 
theory, that acute detachment was due to vitreous fluid passing through a retinal tear into the subretinal space and how he was led by further researches to complete that theory and to extend it to all so-called spontaneous or myopic detachments. In all these forms, the tear being the determining cause of the detachment and hindering it from healing, the most certain way to a definite cure was by scarring up the hole by means of a thermo-cautery when possible. In all recent cases, when the hole has been closed cure is immediate and permanent, and a relapse of the detachment shows that the tear has not been sealed. If the retinal tears are large or multiple treatment takes a long time or may be impossible. The author illustrated by means of drawings, his procedure for localizing the retinal tear and the method of operating, also the ophthalmoscopic appearances of the detached retina before and after the thermopuncture. The following members joined in the discussion, Messrs. Ormond, Goulden, Juler, Hay, Ridley, Sir William Lister, Messis. Haycraft, Gray Clegg, Giri, Harrison Butler, and Lindsay Rea.

On Saturday morning, Mr. HARrison ButLer read a paper on keratoconus posterior, a hitherto undescribed condition discovered by the aid of the slit-lamp. This was discussed by Dr. Marion Gilchrist, Miss Mann, Dr. Traquair, and Mr. Gray Clegg.

Dr. Traguair read notes on new instruments and technique in cataract extraction; the paper was discussed by Mr. GRAY ClEGG. Dr. Derrick Vail, Jr., and Messrs. Greene, Chavasse, Stewart, Curran, and Giri.

Dr. DE COURCY read a paper on interstitial keratitis in workmen's compensation cases. This interesting medico-legal paper attracted much attention and was discussed by Messrs. Harrison Butler, Bickerton, Young, Jacques, Primirose, Kendall, Hay, Alabaster, and the Master.

Dr. van Heuven, of Utrecht, read a short paper on recurrent chronic uveitis, which was illustrated by many excellent lantern slides, and was discussed by Dr. Chavasse.

The proceedings closed on Saturday, July 12, at mid-day, and it was the unanimous opinion that it was the most successful meeting ever held in the history of the Congress. Indeed, the number of members present, namely, 149, greatly exceeded any previous record of the Congress and severely taxed the capacity of the University Anatomy Theatre and the executive staff of the Congress.

G. C. Russ Wood. 